\title{
Cisplatin-induced hair cell loss in zebrafish (Danio rerio) lateral line
}

\author{
Henry C. Ou ${ }^{\text {a,b,d,* }}$, David W. Raible ${ }^{\text {a,c }}$, Edwin W. Rubel ${ }^{\text {a,b }}$ \\ ${ }^{a}$ Virginia Merrill Bloedel Hearing Research Center, University of Washington, Box 357923, Seattle, WA 98195, USA \\ ${ }^{\mathrm{b}}$ Department of Otolaryngology-Head and Neck Surgery, University of Washington, Seattle, WA 98195, USA \\ ${ }^{c}$ Department of Biological Structure, University of Washington, Box 357420, Seattle, WA 98195, USA \\ ${ }^{\mathrm{d}}$ Children's Hospital and Regional Medical Center, Seattle, WA 98105, USA
}

Received 25 May 2007; received in revised form 3 July 2007; accepted 9 July 2007

Available online 19 July 2007

\begin{abstract}
We have used time-lapse imaging to study cisplatin-induced hair cell death in lateral line neuromasts of zebrafish larvae in vivo. We found that cisplatin-induced hair cell death occurred much more slowly than had been shown to occur in aminoglycoside-induced hair cell death. By prelabeling hair cells with FM1-43FX, and assessing hair cell damage, it was established that cisplatin causes hair cell loss in the lateral line in a dose-dependent fashion. The kinetics of hair cell loss during exposure to different concentrations of cisplatin was also assessed and it was found that the onset of hair cell loss correlated with the accumulated dose of cisplatin. These data demonstrate the feasibility and repeatability of cisplatin damage protocols in the zebrafish lateral line and set the stage for future evaluations of modulation of cisplatin-induced hair cell death.
\end{abstract}

(C) 2007 Elsevier B.V. All rights reserved.

Keywords: Hair cell; Cisplatin; Zebrafish; Ototoxicity; Cell death; Lateral line

\section{Introduction}

Ototoxic injury to hair cells is well documented. Two of the most well described ototoxic agents are aminoglycosides and cisplatin. Investigation of these two agents is both clinically important, and may provide insights to general properties underlying hair cell death. Developing damage protocols for these agents in models systems is thus an important step in any research protocol.

While aminoglycosides are still frequently used globally due to their low cost, they are often replaced with effective, albeit more expensive antibiotics such as fluoroquinolones. Cisplatin and other platinum derivatives, on the other hand, are still common components of many chemotherapeutic regimens, with no true alternatives available. Known

\footnotetext{
* Corresponding author. Address: Virginia Merrill Bloedel Hearing Research Center, University of Washington, Box 357923, Seattle, WA 98195, USA. Tel.: +1 206543 8360; fax: +1 2062215685 .

E-mail address: henryou@u.washington.edu (H.C. Ou).
}

to be effective against a variety of adult and pediatric malignancies, the use of cisplatin is still limited by its well known ototoxicity and nephrotoxicity (Reddel et al., 1982; Thompson et al., 1984).

Cisplatin is known to cause hair cell death, with the outer hair cells showing greater susceptibility than inner hair cells; the cisplatin derivative carboplatin is thought to cause primarily inner hair cell death in some species (Takeno et al., 1994; Wake et al., 1993). Cisplatin is also thought to have damaging effects on the stria vascularis, spiral ganglion cells, and possibly the supporting cells of the inner ear (Saito and Aran, 1994; Zheng et al., 1995; Campbell et al., 1999; Cardinaal et al., 2000a; RamirezCamacho et al., 2004). While cisplatin is known to bind DNA and form DNA adducts, causing cell death in mitotically active cells, in mitotically quiescent hair cells it is generally felt that cisplatin induces cell death at least partly by activating reactive oxygen species pathways (Campbell et al., 1996; Rybak et al., 1997; Cardinaal et al., 2000b; Li et al., 2002;). Supporting this hypothesis is evidence that 
antioxidants such as D-methionine, $N$-acetylcysteine, and ebselen are at least partially protective against cisplatininduced hair cell death in several species of mammals (Campbell et al., 1996; Rybak et al., 1997, 2007; Saito et al., 1997).

The zebrafish lateral line is emerging as a useful system for studying hair cells and hair cell loss. Recent studies from our laboratory and others have focused on aminoglycoside-induced hair cell death in the zebrafish (Williams and Holder, 2000; Harris et al., 2003; Murakami et al., 2003; Ton and Parng, 2005; Santos et al., 2006; Owens et al., 2007). The zebrafish offers several advantages to study mechanisms of hair cell toxicity. Like all aquatic vertebrates, they have hair cells on the surface of the body in a sensory system known as the lateral line. These hair cells are organized into clusters of 5-20 hair cells called neuromasts, and are located in stereotypical locations on the head and along the body. Zebrafish lateral line hair cells exhibit selective uptake of a variety of fluorescent vital dyes such as YO-PRO1 and FM1-43. The mechanism of FM143 uptake is likely through the nompC TRP channel (Sidi et al., 2003), while the mechanism of YO-PRO1 uptake in hair cells is unknown. This selective uptake, combined with the optical clarity of the body of young zebrafish allow for rapid in vivo assessment of hair cell death. In addition, ototoxic and potentially protective compounds can be added directly to water, so that precise doseresponse curves can be constructed, and large numbers of hair cells and animals can be assayed.

In this study, we sought to validate the use of larvae zebrafish as a model for investigating hair cell death by studying the specificity of cisplatin toxicity to these hair cells. In addition, we sought to establish protocols for cisplatin damage to zebrafish lateral line hair cells. The results provide evidence that: (1) cisplatin-induced hair cell death occurs in a dose-dependent fashion in the zebrafish lateral line; (2) cisplatin-induced hair cell death can be studied with time-lapse fluorescence microscopy in vivo in this preparation and appears to occur slower than that observed with aminoglycosides; and (3) onset of hair cell death in the zebrafish lateral line correlates with the cumulative dose of cisplatin delivered.

\section{Methods}

All procedures described have been approved by the University of Washington Animal Care and Use Committee.

\subsection{Animals}

Zebrafish (Danio rerio) embryos of the $\mathrm{AB}$ wildtype strain were produced by paired matings of adult fish maintained at $28.5^{\circ} \mathrm{C}$ in the University of Washington zebrafish facility. Embryos were maintained at a density of about 50 embryos per $100 \mathrm{~mm}^{2}$ petri dish in embryo media $(1 \mathrm{mM}$ $\mathrm{MgSO}_{4}, 120 \mu \mathrm{M} \mathrm{KH}{ }_{2} \mathrm{PO} 4,74 \mu \mathrm{M} \mathrm{Na}_{2} \mathrm{HPO}_{4}, 1 \mathrm{mM} \mathrm{CaCl}_{2}$, $500 \mu \mathrm{M} \mathrm{KCl}, 15 \mu \mathrm{M} \mathrm{NaCl}$, and $500 \mu \mathrm{M} \mathrm{NaHCO} 3$ in
$\mathrm{dH}_{2} \mathrm{O}$ ). Beginning at four days post-fertilization (dpf), larvae were fed live paramecia.

\subsection{Labeling protocols}

For time-lapse imaging, live five dpf zebrafish larvae were immersed in $2 \mu \mathrm{M}$ YO-PRO1 (Invitrogen; Y3603) in embryo media for $30 \mathrm{~min}$, then rinsed three times in embryo media. YO-PRO1 used in this fashion selectively labels hair cell nuclei of the lateral line (Santos et al., 2006) and was used only for time-lapse imaging because it allowed better visualization of nuclear changes. For selective labeling of hair cell cytoplasm, live five dpf zebrafish larvae were exposed to $3 \mu \mathrm{M}$ fixable FM1-43FX (Invitrogen; F-35355) for $30 \mathrm{~s}$ followed by three rinses in embryo media. This labeling can be used as a vital dye alone or in conjunction with other fluorophores. In addition, it remains bright and specific to the cytoplasm of the hair cells after fixation. After the various treatments with cisplatin and recovery periods (described below), larvae labeled with FM1-43FX were fixed overnight in 4\% paraformaldehyde at $4{ }^{\circ} \mathrm{C}$, then rinsed in phosphate-buffered saline (PBS) and mounted in Fluoromount-G (SouthernBiotech; 0100-01) for fluorescence microscopy (Fig. 1).

\subsection{Cisplatin damage protocols}

Cisplatin solutions were prepared from powder (Sigma; 33422 ) in embryo medium. Five dpf zebrafish larvae, prelabeled with FM1-43FX were exposed to cisplatin at concentrations of $0,0.25,0.5,0.75,1$, and $1.5 \mathrm{mM}$ for $4 \mathrm{~h}$. Doses were chosen empirically in pilot studies by identifying high doses of cisplatin that caused hair cell death after short durations without mortality of the zebrafish. For these studies, group sizes ranged from 10 to 15 fish. Fish were then fixed overnight at $4{ }^{\circ} \mathrm{C}$ in $4 \%$ paraformaldehyde, rinsed in PBS, and mounted in Fluoromount-G on $25 \times 60 \mathrm{~mm}$ coverslips for imaging. Hair cell counts were determined using fluorescence microscopy to count intact FM1-43FX labeled hair cells from the SO1, SO2, O1 and OC1 (Raible and Kruse, 2000) neuromasts on one side of
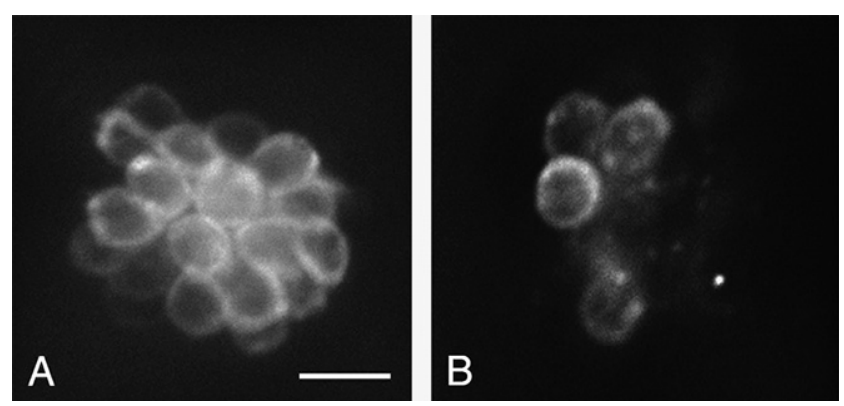

Fig. 1. FM1-43 FX labeled neuromast (OC1) in a fixed zebrafish. Zebrafish were prelabeled with $3 \mu \mathrm{M}$ FM1-43 FX, fixed in 4\% paraformaldehyde, then mounted for fluorescence microscopy. Hair cells are easily counted in undamaged neuromasts (A) and in neuromasts exposed to $1 \mathrm{mM}$ cisplatin for $4 \mathrm{~h}(\mathrm{~B})$. Scale bar $=10 \mu \mathrm{m}$. 
each fish. These neuromasts were selected for cell counts due to their close proximity to one another and their relative ease of imaging in our preparation. Previous work has demonstrated that there is no significant differential sensitivity to aminoglycosides between neuromasts (Harris et al., 2003). Fluorescence microscopy was performed using a Zeiss Axioplan II microscope. Hair cells were counted as surviving if FM1-43FX labeling of the cytoplasm and plasma membrane appeared intact without blebbing or fragmentation. Total hair cell counts were determined by adding the hair cell counts from the four neuromasts. Hair cell survival as a percentage of the control was calculated by dividing the total number of hair cells of each fish in the experimental group by the mean total number of hair cells in a similarly treated control group.

\subsection{Time-lapse microscopy}

Live five dpf zebrafish larvae with hair cells prelabeled with YO-PRO1 were placed in a solution of MS222 (3aminobenzoic acid ethyl ester, methanesulfonate salt, Sigma) anesthetic $(10 \mu \mathrm{g} / \mathrm{ml})$ with or without $1 \mathrm{mM}$ cisplatin in embryo media. For neomycin time-lapse microscopy, five dpf larvae were placed in a solution of MS222 with or without $200 \mu \mathrm{M}$ neomycin in embryo media. A single larva was then placed in a droplet of the MS222/cisplatin or MS222/neomycin solution encircled by vacuum grease on a $24 \times 60 \mathrm{~mm}$ No. 1.5 coverslip. A second coverslip was then placed over the droplet to prevent evaporation. Larvae viability was assessed during imaging by monitoring heartbeat. Zebrafish larvae prepared for imaging in this fashion remain viable for greater than $4 \mathrm{~h}$. Time-lapse imaging was performed using an inverted epifluorescent Zeiss Axiovert $200 \mathrm{M}$ microscope with an automated stage. In most cases neuromasts were viewed with a $40 \mathrm{X}$ objective (N.A. $=0.75$ ). Single images and $z$-series were collected with Slidebook 4.0 software (Intelligent Imaging Innovations, Denver, CO).

\subsection{Statistics}

All values are presented as the mean \pm 1 S.D. Statistical analyses were performed using one-way ANOVA (VassarStats: faculty.Vassar.edu/lowry/VassarStats.html). PostANOVA pairwise analyses were performed using Tukey's HSD test. Results were considered statistically significant if $p<0.05$. Linear least squares regression was performed using Microsoft Excel.

\section{Results}

\subsection{Dose-response curve for cisplatin}

We first tested whether zebrafish lateral line hair cells are killed by cisplatin in a dose-dependent manner. Hair cells in zebrafish larvae at five days post-fertilization (dpf) labeled with FM1-43FX were exposed to cisplatin concen- trations ranging from 0.25 to $1.5 \mathrm{mM}$ for $4 \mathrm{~h}$ and then immediately fixed. Fig. 1 shows an example of FM1-43 FX labeled neuromasts (OC1) in zebrafish fixed in paraformaldehyde in a control subject (A) and after exposure to $1 \mathrm{mM}$ cisplatin (B) for $4 \mathrm{~h}$. There was no general toxicity or mortality at any of the doses, and we did not detect toxicity to any other cell type on the animal's surface. Remaining hair cells were counted in four identified neuromasts (SO1, SO2, O1, OC1; Raible and Kruse, 2000). The results (means \pm 1 S.D.) of this experiment are shown in Fig. 2. Hair cell survival is expressed as a percentage of control animals without cisplatin. In normal animals at this age these four neuromasts have $8( \pm 2), 12( \pm 2), 10( \pm 3)$, and $7( \pm 3)$, hair cells, respectively. We found a robust, dosedependent loss of hair cells in response to cisplatin.

\subsection{Time-lapse imaging of cisplatin-induced hair cell loss}

To follow the time course of hair cell loss by time-lapse microscopy, hair cells in neuromasts of five dpf larvae were first incubated with YOPRO-1. OC1 neuromasts were imaged at 30-min intervals after initiating exposure to $1 \mathrm{mM}$ cisplatin. A representative example is shown in Fig. 3. Morphologic changes of nuclear condensation and fragmentation suggestive of apoptotic cell death are first seen after $30 \mathrm{~min}$ of treatment, and continue through the period of imaging. It is important to note that control five dpf larvae zebrafish treated and imaged in the identical manner without cisplatin exposure demonstrate no hair cell loss during the same time period.

The rate of hair cell loss after cisplatin exposure is much slower than we previously determined for lateral line hair cell loss after exposure to aminoglycoside antibiotics (Santos et al., 2006; Owens et al., 2007). To compare the two treatments, we labeled hair cells with YO-PRO-1 and followed loss after exposure to $200 \mu \mathrm{M}$ neomycin, a dose resulting in near-total hair cell death (Harris et al., 2003). An example is shown in Fig. 4. Nuclear condensation is

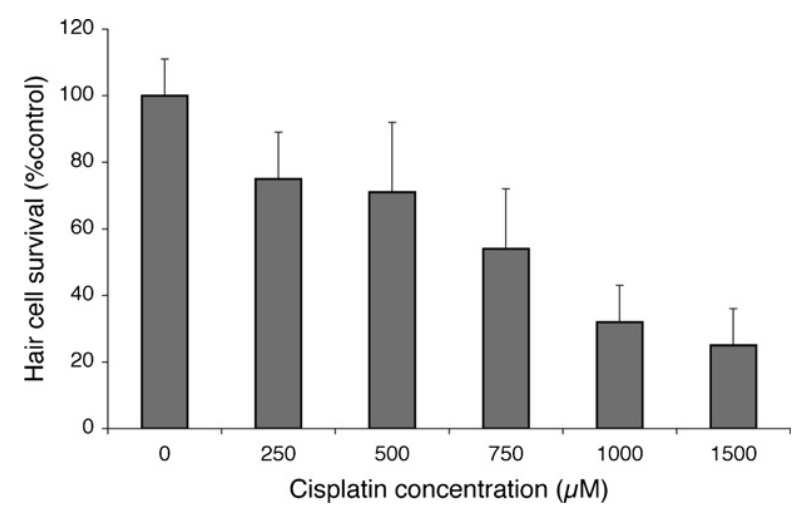

Fig. 2. Cisplatin dose-response relationship. Five day post-fertilization (dpf) zebrafish were prelabeled with FM1-43FX and then exposed to cisplatin for $4 \mathrm{~h}$. Fish were then fixed and hair cells from four neuromasts (SO1, SO2, O1, OC1) were counted. Hair cell survival was calculated as a percentage of the control group (not exposed to cisplatin). Data bars represent the mean hair cell survival ( $n=10$ fish per cisplatin dose) \pm S.D. 

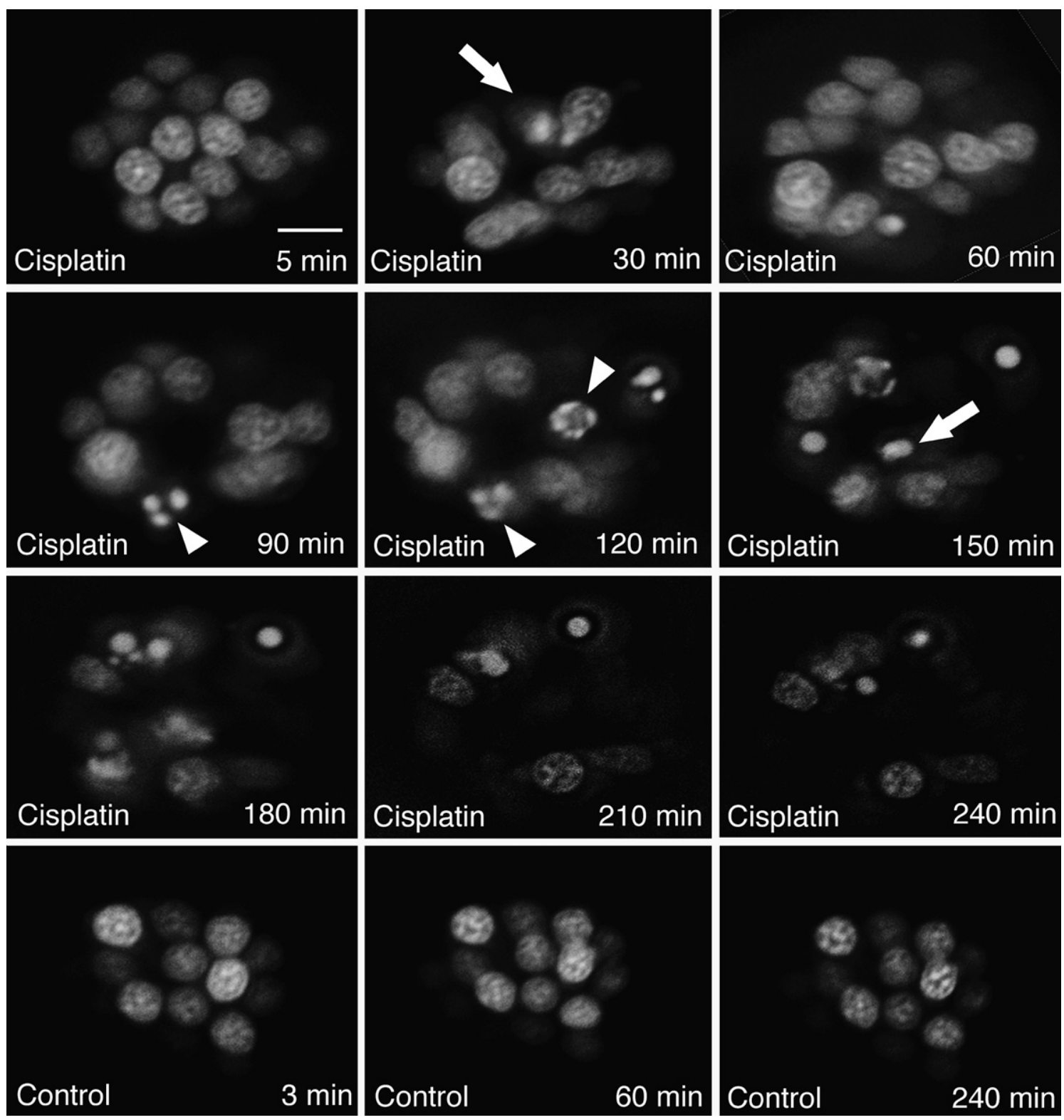

Fig. 3. Time-lapse microscopy of hair cells from single neuromast $(\mathrm{OC} 1)$ in a living zebrafish exposed to cisplatin. Hair cell nuclei were prelabeled with YO-PRO1, exposed to $1 \mathrm{mM}$ cisplatin, and then imaged at $30 \mathrm{~min}$ intervals. The first timepoint measured was at 5 min as this was the time required to anesthetize and prepare the fish for time-lapse imaging. Triangles indicate fragmented nuclei. Arrows indicate condensed nuclei. The bottom three panels are images from an unexposed control, demonstrating no significant hair cell loss over 240 min of imaging. Scale bar $=10 \mu \mathrm{m}$.

observed as early as 5 min after treatment, and hair cell loss is essentially complete by 50 min of exposure at this neomycin dose.

\subsection{Relationship between dose and time}

The relative delay in hair cell death with cisplatin treatment when compared to neomycin exposure is consistent with previous studies that have suggested that cisplatin has cumulative effects (Bokemeyer et al., 1998; Helson et al., 1978). We therefore evaluated the relationship between cisplatin concentration and exposure time. Fig. 5 shows the results of this analysis. Fish at five dpf were con- tinuously exposed to cisplatin doses between 0.05 and $1 \mathrm{mM}$ concentrations. Different groups of fish $(N=10-15$ fish) were then examined at time intervals between 1 and $12 \mathrm{~h}$. There was no mortality of larvae at any of the cisplatin doses or time-points. As can be seen from Fig. 5, both dose and time of exposure dramatically and independently influence the amount of hair cell loss: low doses and longer times of exposure are as effective at killing hair cells as high doses for shorter times.

The relationship between time of exposure and cisplatin concentration can be evaluated more directly by calculating the exposure duration required to cause $50 \%$ hair cell loss, or $t_{1 / 2}$. These data for cisplatin concentrations between 

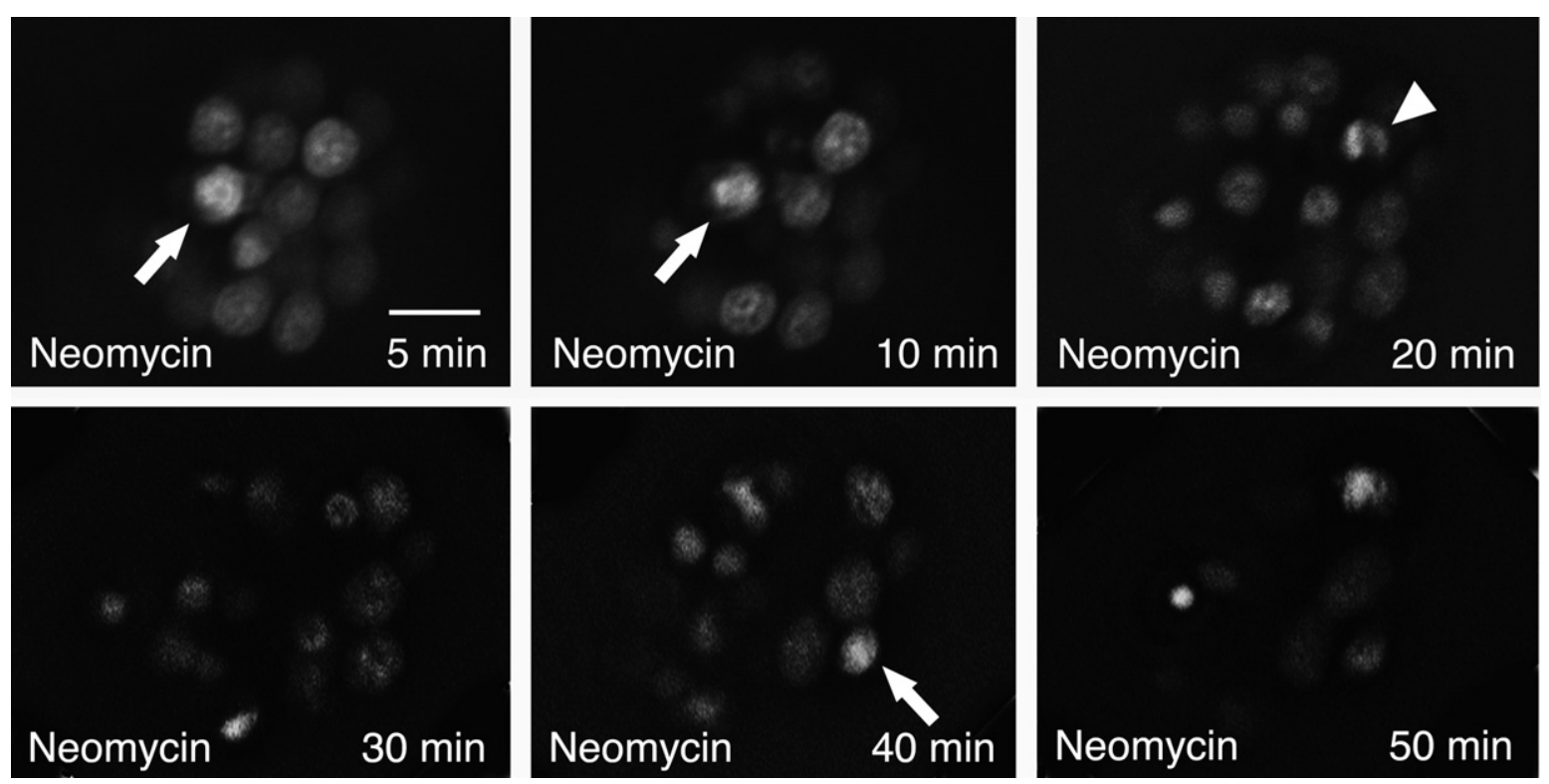

Fig. 4. Time-lapse microscopy of hair cells from single neuromast $(\mathrm{OC} 1)$ in a living zebrafish exposed to neomycin. Hair cell nuclei were prelabeled with YO-PRO1, exposed to $200 \mu \mathrm{M}$ neomycin, and imaged at the labeled time-points. The first timepoint measured was at 5 min as this was the time required to anesthetize and prepare the fish for time-lapse imaging. Note that as early as 5 min there was already evidence of hair cell damage. Overall, morphologic changes of hair cell death after neomycin treatment were seen much more rapidly than were seen during cisplatin exposure in Fig. 3 . Triangles indicate fragmented nuclei. Arrows indicate condensed nuclei. Scale bar $=10 \mu \mathrm{m}$.

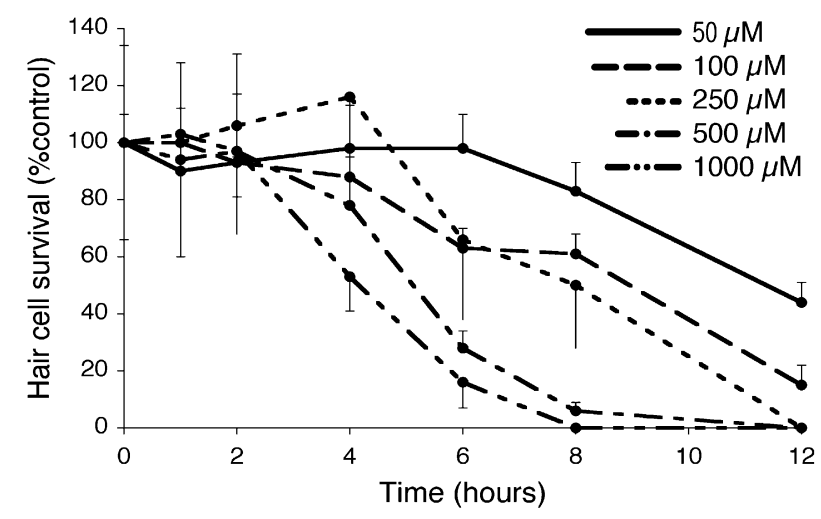

Fig. 5. Cisplatin hair cell survival curves with variable cisplatin doses. Five dpf zebrafish larvae were labeled with FM1-43FX and then exposed to cisplatin at $50 \mu \mathrm{M}$ (solid line), $100 \mu \mathrm{M}(-\ldots-$ ), $250 \mu \mathrm{M}(-\ldots)$, $500 \mu \mathrm{M}\left({ }_{-}-\right)$, and $1000 \mu \mathrm{M}\left(--_{-}\right)$. Fish were then removed after 1 , $2,4,6,8$, and $12 \mathrm{~h}$ of continuous cisplatin exposure. Hair cell survival was calculated as a percentage of the control group (not exposed to cisplatin). Data points represent the mean value $(n=10$ fish, per concentration and timepoint) \pm S.D.

$50 \mu \mathrm{M}$ and $1 \mathrm{mM}$ are shown in Table 1 and Fig. 6. A linear regression was calculated for each cisplatin concentration. The resulting regression was used to calculate the time required to produce $50 \%$ hair cell loss, $t_{1 / 2}$. Table 1 provides the estimates of rates of hair cell loss at each dosage and results of regression analyses. As shown in Fig. 6 the $t_{1 /}$ 2 plotted against cisplatin concentration on a logarithmic scale produced a very tight linear function with an $r^{2}$ of 0.97 . Table 1 also suggests that once hair cell loss is initiated (determined by the onset of hair cell loss on the dose-response curve), the rate of loss appears independent
Table 1

Kinetics of hair cell loss for variable cisplatin doses

\begin{tabular}{ccl}
\hline Cisplatin concentration $(\mu \mathrm{M})$ & $t_{1 / 2}(\mathrm{~h})$ & $\%$ Total hair cells lost $/ \mathrm{h}\left(r^{2}\right)$ \\
\hline 50 & 11.6 & $9 \% / \mathrm{h}(0.84)$ \\
100 & 9.6 & $9 \% / \mathrm{h}(0.90)$ \\
250 & 8.5 & $11 \% / \mathrm{h}(0.67)$ \\
500 & 5.6 & $18 \% / \mathrm{h}(0.83)$ \\
1000 & 5.1 & $16 \% / \mathrm{h}(0.89)$ \\
\hline
\end{tabular}

$t_{1 / 2}$ represents the time in hours required to achieve $50 \%$ hair cell loss based on linear regression analysis. The rate of hair cell loss once hair cell loss was initiated was determined by linear regression of data points from Fig. 5 and is shown as the slope of hair cell loss versus time, or the percent hair cell loss per hour $\left(r^{2}\right)$.

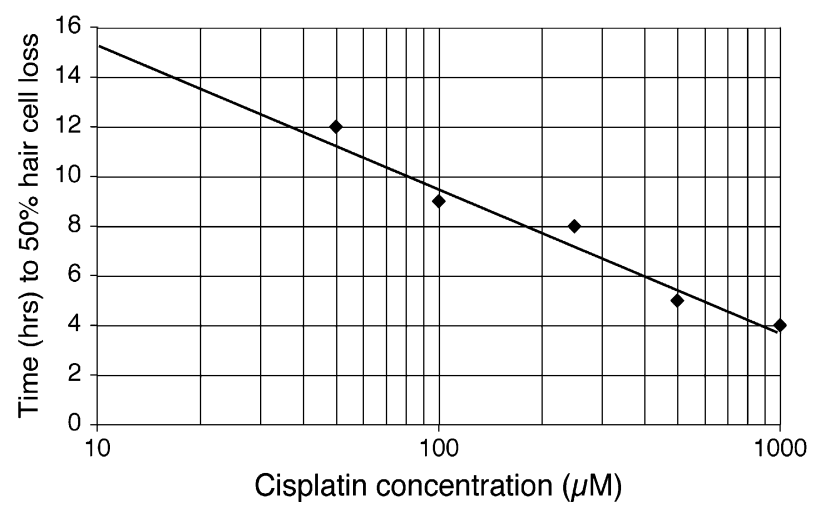

Fig. 6. Linear regression of time required to achieve $50 \%$ hair cell loss as a function of cisplatin concentration $\left(t_{1 / 2}\right)$. Cisplatin concentration is plotted on a logarithmic scale. Data points were calculated from linear regression functions from Table 1. Regression line depicted is represented by the formula $t_{1 / 2}=-5.5 \log (\mu \mathrm{M}$ cisplatin $)+20\left(r^{2}=0.97\right)$. 
of the concentration. The slopes of the hair cell loss functions are consistent with a model where hair cells are lost once enough cisplatin has accumulated, independent of dose or time.

\subsection{Hair cell loss continues after withdrawal of cisplatin}

To further assess the progression of hair cell loss after the initial cisplatin exposure, five dpf zebrafish larvae were treated first with $1 \mathrm{mM}$ cisplatin for $2 \mathrm{~h}$. Note that this is a dose of cisplatin that causes extensive hair cell loss after $4 \mathrm{~h}$, but no significant hair cell loss at $2 \mathrm{~h}$ (Fig. 5). Some fish were then rinsed in embryo media and allowed to recover for 4 or $24 \mathrm{~h}$ in embryo media before analysis. Data from these groups were compared to results from control (untreated) fish, fish fixed immediately after treatment with $1 \mathrm{mM}$ cisplatin for $2 \mathrm{~h}$ (no recovery period), as well as fish continuously exposed to cisplatin for $6 \mathrm{~h}$. Hair cell counts for approximately 10 fish per group were assessed by fluorescence microscopy.

Fig. 7 compares the hair cell survival (percent of control) of these five groups. Hair cell survival after $2 \mathrm{~h}$ of cisplatin and $4 \mathrm{~h}$ of recovery is significantly lower than survival immediately after the $2 \mathrm{~h}$ exposure to cisplatin, demonstrating that hair cell loss continues after withdrawal of cisplatin (one-way ANOVA, $p<0.01$ ). Not surprisingly, hair cell survival in the fish exposed to $2 \mathrm{~h}$ of cisplatin followed by $4 \mathrm{~h}$ of recovery is higher than that of fish exposed to $6 \mathrm{~h}$ of continuous cisplatin (one-way ANOVA, $p<0.01$ ). Hair cell survival after $24 \mathrm{~h}$ of recovery is not significantly different from hair cell survival after $4 \mathrm{~h}$ of recovery, indicating that the majority of hair cell loss is complete after $4 \mathrm{~h}$ of recovery. These data suggest that cell death pathways triggered after $2 \mathrm{~h}$ of cisplatin are likely completed within $4 \mathrm{~h}$. Note, that while hair cell regeneration does

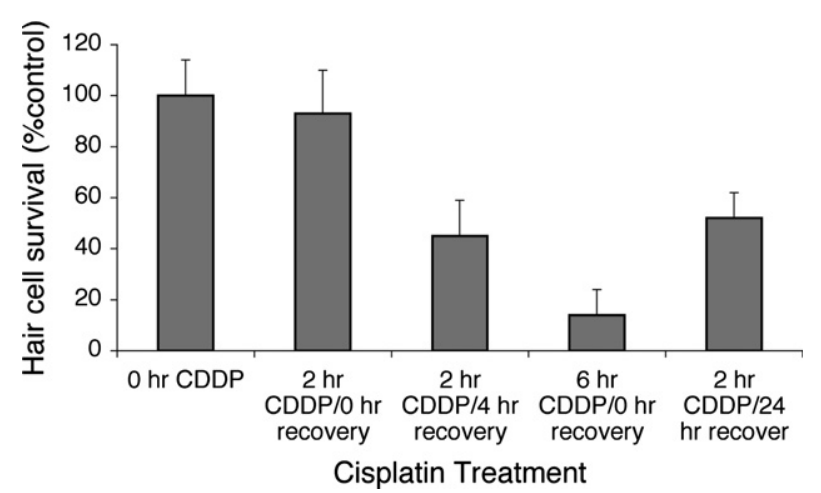

Fig. 7. Hair cell survival after treatment with $1 \mathrm{mM}$ cisplatin for $2 \mathrm{~h}$ followed by variable recovery periods. Data bars represent mean hair cell survival $(n=10$ fish $) \pm$ S.D. for each treatment condition. After $2 \mathrm{~h}$ of cisplatin (CDDP) and no recovery, there was minimal hair cell loss. After $4 \mathrm{~h}$ of recovery, there was progressive hair cell loss (one-way ANOVA, $p<0.01$ ). Extending recovery for $24 \mathrm{~h}$ resulted in no significant additional hair cell loss. Six hours of continuous cisplatin showed additional damage compared to $2 \mathrm{~h}$ of cisplatin with $4 \mathrm{~h}$ of recovery (one-way ANOVA, $p<0.01)$. occur in the lateral line (Harris et al., 2003), since existing hair cells were pre-labeled with FM1-43FX prior to cisplatin exposure and recovery, newly regenerated hair cells would not be fluorescently labeled at the time of this analysis.

\section{Discussion}

This study establishes that cisplatin causes repeatable and predictable damage to zebrafish lateral line hair cells, defines the time course of hair cell loss, and demonstrates that the kinetics of hair cell loss in response to low and high dose cisplatin follows a mathematically predictable relationship. Recent work from our laboratory and others has established the zebrafish lateral line as a model system for studying aminoglycoside-induced hair cell death (Harris et al., 2003; Murakami et al., 2003; Ton and Parng, 2005; Linbo et al., 2006; Santos et al., 2006; Owens et al., 2007). The present study provides additional support for the validity and utility of the zebrafish lateral line as an accessible preparation for studying mechanosensory hair cell death from a variety of challenges.

Time-lapse data from this study indicate that cisplatin damage occurs over a much longer time period than neomycin damage. There are several possible reasons why the time course for cisplatin-induced damage is slower. One mechanism might be different rates of uptake. While the mechanisms of aminoglycoside uptake in hair cells is known to be rapid in mammalian inner ear hair cells (Steyger et al., 2003) as well as zebrafish lateral line hair cells (Santos et al., 2006), relatively little is known regarding the kinetics or mechanisms of cisplatin uptake by hair cells. In vitro, cisplatin is known to enter murine fibroblast cell lines at least partially via the CTR 1 copper influx transporter (Holzer et al., 2006). The CTR1 transporter is known to be widely expressed in early stage zebrafish, although its specific expression in hair cell membranes is not characterized (Mackenzie et al., 2004). Once uptake occurs, the mechanisms of cell injury and death also likely differ between aminoglycosides and cisplatin. There is some suggestion that neomycin and cisplatin act through different apoptotic pathways; e.g., Jun kinase inhibition blocks neomycin but not cisplatin-induced hair cell death (Wang et al., 2004; Ou et al., 2006). On the other hand, it should be noted that there is evidence that reactive oxygen species play important roles in both aminoglycoside and cisplatininduced hair cell death (Hirose et al., 1997, 1999; Sha and Schacht, 2000; Cardinaal et al., 2000b; Li et al., 2002; Minami et al., 2004). Finally, there may be different rates of clearance or degradation in cells, which would influence whether toxicity is cumulative or acute.

Our data are consistent with a cumulative model for cisplatin-induced hair cell loss. Cisplatin toxicity has been associated with peak plasma levels (Nagai et al., 1996) and with plasma area under the concentration-time curve (Ozawa et al., 1988; Nagai and Ogata, 1997) in cancer models of cisplatin toxicity. Bokemeyer et al. (1998) studying 
patients with testicular cancer found that ototoxicity correlated strongly with the cumulative dose of cisplatin. Since the lateral line hair cells are external, it can be assumed that there is a constant extracellular concentration of cisplatin, and thus the area under the curve is simply the concentration multiplied by the exposure time. The data presented here demonstrate that low doses of cisplatin given continuously over a long duration can cause equivalent amounts of hair cell loss as high doses delivered over shorter durations. The $t_{1 / 2}$ (time required for $50 \%$ hair cell loss) did not correlate linearly with the area under the curve, but did correlate well with concentration on a logarithmic scale $\left(r^{2}=0.97\right)$. While not conclusive, this relationship is consistent with a drug accumulation model of cisplatin damage in hair cells, where hair cell death is initiated once cisplatin uptake has exceeded a critical intracellular concentration. In addition, based on the linear regression analysis in Table 1, once the first signs of hair cell death are apparent, the kinetics of hair cell loss are independent of cisplatin concentration. This interpretation is supported by the similar rates of hair cell loss once cell death had been initiated. This finding is significant in that it addresses concerns over whether the surprisingly rapid hair cell death observed in the zebrafish lateral line is secondary to exposure to unnaturally high drug levels, and possibly activation of other apoptotic or necrotic cell death pathways. Our finding here that low and high dose cisplatin damage obey predictable and similar hair cell death kinetics suggests that higher doses of cisplatin simply result in earlier initiation of a cell death cascade. These more time-efficient, high dose, short duration damage protocols may therefore be acceptable models for studying cisplatin-induced hair cell damage in the zebrafish lateral line. This may be a particularly valuable model because most in vivo mammalian preparations in which cisplatin-induced hair cell death is studied require multiple days of cisplatin exposure (Cardinaal et al., 2000b; Li et al., 2002; Minami et al., 2004). While the gold standard with respect to human health is clearly what happens in the mammalian inner ear, development of more rapid damage protocols in zebrafish paves the way for future high throughput investigations into modulation of cisplatininduced hair cell death.

\subsection{Caveats}

While we believe that the zebrafish lateral line is a valuable system for studying hair cells and hair cell loss, there are certainly drawbacks that must be kept in mind. In contrast to the inner ear, hair cells of the lateral line have no stria vascularis or spiral ganglia, which are known targets of cisplatin, nor are there compartmentalized fluids such as perilymph and endolymph. In addition, while the basic mechanisms of hair cell sensitivity to cisplatin are likely to be universal, lateral line hair cells are morphologically and physiologically much more similar to vestibular than cochlear hair cells of the mammalian inner ear. Hence, to the extent that cisplatin exposure differentially affects these two hair cell populations, we would expect results in this model system to be more predictable of the outcomes for vestibular epithelium. No ultrastructural analysis is included here, however loss of FM1-43FX staining clearly correlates well with actual $\mathrm{HC}$ loss, and nuclear staining with YO-PRO1 shows clear histologic findings consistent with an apoptotic-like program of cell death (nuclear condensation and fragmentation).

\section{Conclusion}

This study demonstrates the value of the zebrafish for studying hair cell death. Due to the availability of large numbers of animal subjects, as well as the ease of hair cell assessment, experiments with a large number of time-points and concentrations are possible. Access to hair cells on the body surface allows precise determination of times of drug exposure. In addition, this study demonstrates that while cisplatin-induced hair cell death appears to occur slower than aminoglycoside-induced hair cell death in the zebrafish lateral line, fairly rapid $(<4 \mathrm{~h})$ cisplatin damage protocols are feasible and useful. These experiments provide a baseline for rapid and simple protocols to assess modulation of cisplatin-induced hair cell death in the zebrafish lateral line.

\section{Acknowledgments}

The authors thank Glen MacDonald for his help with imaging, and Brock Roberts for his excellent technical support. This work was supported by NIH Grants DC05987, DC04661 and DC00018.

\section{References}

Bokemeyer, C., Hartmann, J.T., Kuczyk, M.A., Truss, M.C., Kollmannsberger, C., Beyer, J., Jonas, U., Kanz, L., 1998. Recent strategies for the use of paclitaxel in the treatment of urological malignancies. World J. Urol. 16, 155-162.

Campbell, K.C., Meech, R.P., Rybak, L.P., Hughes, L.F., 1999. DMethionine protects against cisplatin damage to the stria vascularis. Hear. Res. 138, 13-28.

Campbell, K.C., Rybak, L.P., Meech, R.P., Hughes, L., 1996. Dmethionine provides excellent protection from cisplatin ototoxicity in the rat. Hear. Res. 102, 90-98.

Cardinaal, R.M., de Groot, J.C., Huizing, E.H., Veldman, J.E., Smoorenburg, G.F., 2000a. Cisplatin-induced ototoxicity: morphological evidence of spontaneous outer hair cell recovery in albino guinea pigs? Hear. Res. 144, 147-156.

Cardinaal, R.M., de Groot, J.C., Huizing, E.H., Veldman, J.E., Smoorenburg, G.F., 2000b. Histological effects of co-administration of an $\operatorname{ACTH}((4-9))$ analogue, ORG 2766, on cisplatin ototoxicity in the albino guinea pig. Hear. Res. 144, 157-167.

Harris, J.A., Cheng, A.G., Cunningham, L.L., MacDonald, G., Raible, D.W., Rubel, E.W., 2003. Neomycin-induced hair cell death and rapid regeneration in the lateral line of zebrafish (Danio rerio). J. Assoc. Res. Otolaryngol. 4, 219-234.

Helson, L., Okonkwo, E., Anton, L., Cvitkovic, E., 1978. cis-Platinum ototoxicity. Clin. Toxicol. 13, 469-478. 
Hirose, K., Hockenbery, D.M., Rubel, E.W., 1997. Reactive oxygen species in chick hair cells afger gentamicin exposure in vitro. Hear. Res. 104, 1-14.

Hirose, K., Westrum, L.E., Stone, J.S., Zirpel, L., Rubel, E.W., 1999. Dynamic studies of ototoxicity in mature avian auditory epithelium. Ann. N. Y. Acad. Sci. 884, 389-409.

Holzer, A.K., Manorek, G.H., Howell, S.B., 2006. Contribution of the major copper influx transporter CTR 1 to the cellular accumulation of cisplatin, carboplatin, and oxaliplatin. Mol. Pharmacol. 70, 13901394.

Li, G., Sha, S.H., Zotova, E., Arezzo, J., Van de Water, T., Schacht, J., 2002. Salicylate protects hearing and kidney function from cisplatin toxicity without compromising its oncolytic action. Lab. Invest. 82, $585-596$.

Linbo, T.L., Stehr, C.M., Incardona, J.P., Scholz, N.L., 2006. Dissolved copper triggers cell death in the peripheral mechanosensory system of larval fish. Environ. Toxicol. Chem. 25, 597-603.

Mackenzie, N.C., Brito, M., Reyes, A.E., Allende, M.L., 2004. Cloning, expression pattern and essentiality of the high-affinity copper transporter 1 (ctr1) gene in zebrafish. Gene 328, 113-120.

Minami, S.B., Sha, S.H., Schacht, J., 2004. Antioxidant protection in a new animal model of cisplatin-induced ototoxicity. Hear. Res. 198, $137-143$.

Murakami, S.L., Cunningham, L.L., Werner, L.A., Bauer, E., Pujol, R., Raible, D.W., Rubel, E.W., 2003. Developmental differences in susceptibility to neomycin-induced hair cell death in the lateral line neuromasts of zebrafish (Danio rerio). Hear. Res. 186, 47-56.

Nagai, N., Kinoshita, M., Ogata, H., Tsujino, D., Wada, Y., Someya, K., Ohno, T., Masuhara, K., Tanaka, Y., Kato, K., Nagai, H., Yokoyama, A., Kurita, Y., 1996. Relationship between pharmacokinetics of unchanged cisplatin and nephrotoxicity after intravenous infusions of cisplatin to cancer patients. Cancer Chemother. Pharmacol. 39, 131-137.

Nagai, N., Ogata, H., 1997. Quantitative relationship between pharmacokinetics of unchanged cisplatin and nephrotoxicity in rats: importance of area under the concentration-time curve (AUC) as the major toxicodynamic determinant in vivo. Cancer Chemother. Pharmacol. 40, 11-18.

Ou, H.C., Santos, F., Raible, D.W., Rubel, E.W., 2006. c-Jun N-terminal kinase inhibition blocks aminoglycoside but not cisplatin-induced hair cell death in the zebrafish lateral line. Midwinter Research Meeting of the Association for Research in Otolaryngology.

Owens, K.N., Cunningham, D.E., MacDonald, G., Rubel, E.W., Raible, D.W., Pujol, R., 2007. Ultrastructural analysis of aminoglycosideinduced hair cell death in the zebrafish lateral line reveals an early mitochondrial response. J. Comp. Neurol. 502, 522-543.

Ozawa, S., Sugiyama, Y., Mitsuhashi, Y., Kobayashi, T., Inaba, M., 1988. Cell killing action of cell cycle phase-non-specific antitumor agents is dependent on concentration-time product. Cancer Chemother. Pharmacol. 21, 185-190.

Raible, D.W., Kruse, G.J., 2000. Organization of the lateral line system in embryonic zebrafish. J. Comp. Neurol. 421, 189-198.

Ramirez-Camacho, R., Garcia-Berrocal, J.R., Bujan, J., Martin-Marero, A., Trinidad, A., 2004. Supporting cells as a target of cisplatin-induced inner ear damage: therapeutic implications. Laryngoscope 114, 533537.

Reddel, R.R., Kefford, R.F., Grant, J.M., Coates, A.S., Fox, R.M., Tattersall, M.H., 1982. Ototoxicity in patients receiving cisplatin: importance of dose and method of drug administration. Cancer Treat. Rep. 66, 19-23.

Rybak, L.P., Husain, K., Evenson, L., Morris, C., Whitworth, C., Somani, S.M., 1997. Protection by 4-methylthiobenzoic acid against cisplatin-induced ototoxicity: antioxidant system. Pharmacol. Toxicol. 81, 173-179.

Rybak, L.P., Whitworth, C.A., Mukherjea, D., Ramkumar, V., 2007. Mechanisms of cisplatin-induced ototoxicity and prevention. Hear. Res. 226, 157-167.

Saito, T., Aran, J.M., 1994. Comparative ototoxicity of cisplatin during aute and chronic treatment. ORL J. Otorhinolaryngol. Relat. Spec. 56, $315-320$.

Saito, T., Zhang, Z.J., Manabe, Y., Ohtsubo, T., Saito, H., 1997. The effect of sodium thiosulfate on ototoxicity and pharmacokinetics after cisplatin treatment in guinea pigs. Eur. Arch. Otorhinolaryngol. 254, 281-286.

Santos, F., Mcdonald, G., Rubel, E.W., Raible, D.W., 2006. Lateral line hair cell maturation is a determinant of aminoglycoside susceptibility in zebrafish (Danio rerio). Hear. Res. 213, 25-33.

Sha, S.H., Schacht, J., 2000. Antioxidants attenuate gentamicin-induced free radical formation in vitro and ototoxicity in vivo: D-methionine is a potential protectant. Hear. Res. 142, 34-40.

Sidi, S., Friedrich, R.W., Nicolson, T., 2003. NompC TRP channel required for vertebrate sensory hair cell mechanotransduction. Science 301, 96-99.

Steyger, P.S., Peters, S.L., Rehling, J., Hordichok, A., Dai, C.F., 2003. Uptake of gentamicin by bullfrog saccular hair cells in vitro. J. Assoc. Res. Otolaryngol. 4, 565-578.

Takeno, S., Harrison, R.V., Mount, R.J., Wake, M., Harada, Y., 1994. Induction of selective inner hair cell damage by carboplatin. Scan. Micros. 8, 97-106.

Thompson, S.W., Davis, L.E., Kornfeld, M., Hilgers, R.D., Standefer, J.C., 1984. Cisplatin neuropathy. Clinical, electrophysiologic, morphologic, and toxicologic studies. Cancer 54, 1269-1275.

Ton, C., Parng, C., 2005. The use of zebrafish for assessing ototoxic and otoprotective agents. Hear. Res. 208, 79-88.

Wake, M., Takeno, S., Ibrahim, D., Harrison, R., Mount, R., 1993. Carboplatin ototoxicity: an animal model. J. Laryngol. Otol. 107, 585589

Wang, J., Ladrech, S., Pujol, R., Brabet, P., Van De Water, T.R., Puel, J.L., 2004. Caspase inhibitors, but not c-Jun NH2-terminal kinase inhibitor treatment, prevent cisplatin-induced hearing loss. Cancer Res. 64, 9217-9224.

Williams, J.A., Holder, N., 2000. Cell turnover in neuromasts of zebrafish larvae. Hear. Res. 143, 171-181.

Zheng, J.L., Stewart, R.R., Gao, W.Q., 1995. Neurotrophin-4/5 enhances survival of cultured spiral ganglion neurons and protects them from cisplatin neurotoxicity. J. Neurosci. 15, 5079-5087. 